$>$ and 'quintessence', a fifth element (in addition to the familiar earth, air, fire and water), which was needed to keep the theory consistent, explaining, for example, why heavenly bodies move in circles rather than in straight lines.

Physica did not become physics simply as a result of observant people adding pieces to a puzzle. It required transformations in the social ecosystem, such as who pays for knowledge and why; its social applications; and how it is communicated. Physica got a big boost from the Islamic world, where Aristotle's concept was highly regarded and translated into Arabic around the ninth century. But physics began to acquire its eventual outline in the West after the sixteenth century, with the generation of Francis Bacon, Galileo and René Descartes.

Fostered by the needs of centralized, bureaucratic states, the discovery of new worlds, the spread of universities and new industrial applications, the emergence of physics as we know it today was a process of "dedeifying and deanthropomorphizing nature". Now, God is marginalized and 'dark energy', our new quintessence, is needed to make sense of it all. A theory of everything is an ever more remote goal.

Heilbron does not sneer at physica, but carefully examines it and the ecosystem in which it thrived. By the book's end, physics has split off into so many branches - radar, Earth science, space probes, accelerators, meteorology and so on permeating so many spheres of human life that we begin to lose sight of the field as something coherent. And that is the point.

Whereas Rovelli's feel-good book ends with us gazing in wonder at the edge of "the ocean of the unknown", Heilbron leaves us rooted in lived reality. "Physics has given civilization a somber, disturbing, and challenging world picture, many fertile and some terrifying inventions, and notice of responsibility for the outcome of the human story." If it, too, outsells Fifty Shades, there is hope for humanity yet.

Robert P. Crease is a professor in the Department of Philosophy at Stony Brook University, New York. e-mail:robert.crease@stonybrook.edu

\title{
GEOENGINEERING
}

\section{Journey into geopoetry}

\section{Jane C. S. Long relishes an erudite exploration of the people and principles of climate intervention.}

$\mathrm{S}$ everal authors have tackled geoengineering - the idea of harnessing science and technology to cool our overheated planet. In the 2010 How to Cool the Planet (Houghton Mifflin Harcourt), Jeff Goodell told the personal stories of geoengineers. One, physicist David Keith, described how his interest in climate modification is grounded in a desire to preserve nature in A Case for Climate Engineering (MIT Press, 2013). Jack Stilgoe discussed responsible governance of geoengineering in Experiment Earth (Routledge, 2015). Eli Kintisch covered the history of potential solutions and their developers in Hack the Planet (Wiley, 2010). Stewart Brand described intervention as inevitable in Whole Earth Discipline (Atlantic, 2010), stating: "We are as gods and we might as well get good at it."

But if you are going to read one book on climate engineering, it should be The Planet Remade. Oliver Morton, briefings editor at The Economist, starts by asking: do you think climate change is a problem, and the energy system easy to change? Using this dialectic, he explores the thesis that the climate crisis cannot be solved, but could be managed. There follows a journey through the people and principles of climate science and intervention, the natural history of carbon dioxide, engineering of the nitrogen cycle and the backstory of weather modification. Morton speculates about the ethical, political and social implications if climate intervention became available. The book finishes with a range of scenarios - including one that could end well for Earth and a frank discussion of what could go wrong. The Planet Remade is as much an exploration of science and

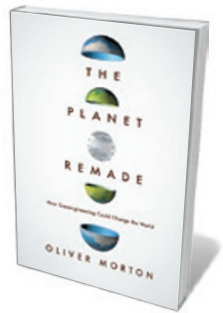

The Planet

Remade: How

Geoengineering

Could Change the World

OLIVER MORTON Granta: 2015. engineering as it is of people and attitudes.

Most climate engineering proposes to change the radiation balance of Earth so that less radiation gets in, or more escapes. Techniques include spraying reflective aerosols into the stratosphere, brightening clouds with salt spray or sequestering greenhouse gases.

Morton traces the idea to the cold war, when scientists including physicist Edward Teller began to fear that a nuclear war would cause a hellish conflagration, darkening the skies and creating a 'nuclear winter'. Efforts to understand this led to the birth of modern climate science — which in turn supported 1980s warnings about climate change by the likes of atmospheric physicists James Hansen and Stephen Schneider. Given clear evidence that volcanic eruptions can send enough reflecting sulfur particles into the stratosphere to cool Earth noticeably, it was not a great leap for some scientists to contemplate intentionally using sulfur to counteract greenhouse-gas emissions. The Planet Remade encourages researching this idea and others to learn more about their effectiveness, feasibility and advisability.

Climate engineering evokes very disparate and strong reactions. As Morton shows, some people, such as Keith, are keen to start intervention, whereas others, such as ethicist Clive

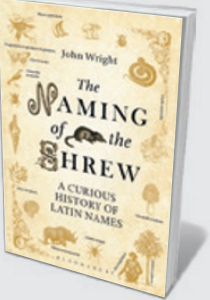

The Naming of the Shrew: A Curious History of Latin Names John Wright (Bloomsbury, 2015) Ba humbugi is not a curse but a snail, and bananas are a "taxonomic nightmare". Fungus fanatic John Wright digs into taxonomy's origins, including Carl Linnaeus's overtly sexual plantordering system, based on reproductive parts.

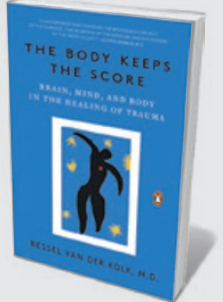

The Body Keeps the Score: Brain, Mind, and Body in the Healing of Trauma Bessel van der Kolk (Viking, 2015) Violence, abuse or conflict can burn trauma into memory. Psychiatrist Bessel van der Kolk reveals how severe stress rewires the brain, and suggests therapies from breathing techniques to eyemovement desensitization and reprocessing. 


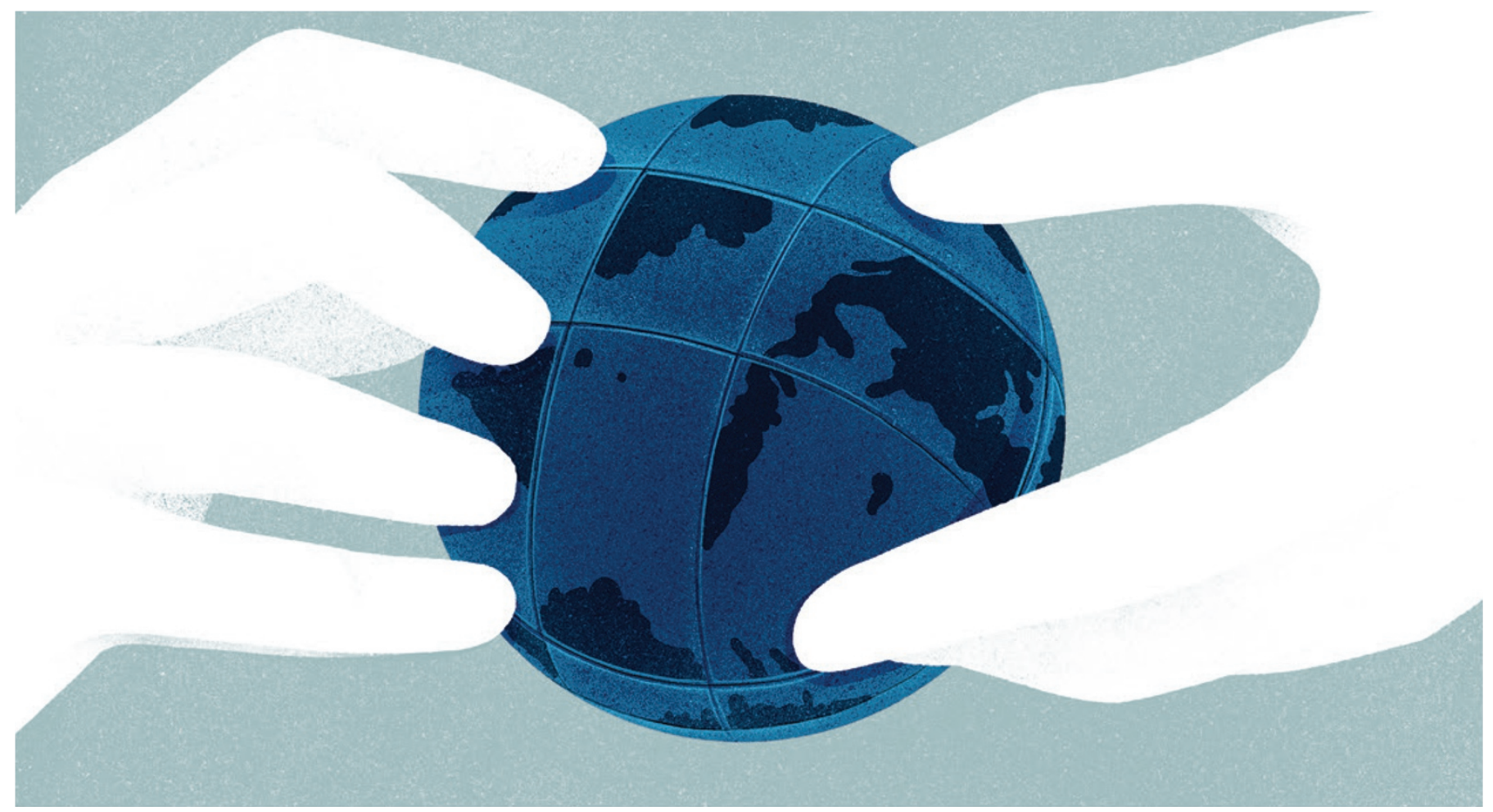

Hamilton, abhor the enterprise. Brand feels that the only option is to manage the global environment - which many fear would fail, because humanity lacks the wisdom and capability for the task. Morton weighs these perspectives with sympathy. He takes pains to find value in each, while maintaining his own insight gleaned from knowledge of the natural world, social thought, literature and science fiction, science and politics, scientific history and the scientists making that history. Lively anecdotes make clear that, as a journalist, Morton has known many of these people personally. Who else could tell us that the substance ice-nine in Kurt Vonnegut's novel Cat's Cradle (Holt, Rinehart \& Wilson, 1963) was based on cloud-seeding research by the novelist's brother, Bernie?

His prose is sometimes hard to parse, but poetic - or "geopoetic", as he would have it. In a moving passage, Morton explains that he has not said "we" because the world population has yet to unite to counterbalance climate change, although he hopes that it will. His hope is embodied in the beauty of elegant engineering and joy in a world of thriving life:

\section{THE WORLD POPULATION HAS YET TO UNITE TOCOUNTERBALANCE CLIMATE CHANGE.}

"a reimagining of how humans and nature can intermingle, a new consciousness of what can be done for the planet rather than a blind deference to what are claimed to be its limits". He sees the future as creating "a we ... that can set a better course". I share Morton's belief that contemplating climate intervention could help humanity to become a "we" that acts on the need to take responsibility for our planet, with or without geoengineering.

For a potentially harrowing topic, serendipity and fun abound. Plentiful and erudite footnotes are richly entertaining. To quote a favourite, in discussing controversy over defining the start of the human-influenced
Anthropocene epoch, Morton notes: "when scientific publications refer to an event happening 2,500 or 5,000 years 'before present' (BP), they actually mean before 1950. If 1950 were chosen as the beginning of the Anthropocene, then the Anthropocene would ... be in a condition of permanent futurity, hanging unsupported in the air like a Wile E. Coyote that has run over the cliff at the end of history."

Who should read The Planet Remade? In some ways it is too technical for a lay audience, but too important to be reserved for experts. Anyone with a knowledge of the climate problem would benefit; it also works as a primer on energy, climate science and Earth-system science. I have a long list of people to whom I will be recommending it.

Jane C. S. Long works on reinvention of the energy system and geoengineering. She has retired as associate director for energy and environment at Lawrence Livermore National Laboratory in California, and was formerly dean of the Mackay School of Mines at the University of Nevada, Reno. e-mail:janecslong@gmail.com

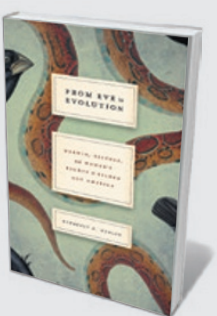

From Eve to Evolution

Kimberly A. Hamlin (Univ. Chicago Press, 2015)

Science historian Kimberly Hamlin shows how nineteenth-century US feminists used Darwinian evolutionary theory to argue for equality. Eliza Gamble, for example, put women's choice at the forefront of male-female attraction (see Sarah S. Richardson's review: Nature 509, 424; 2014).

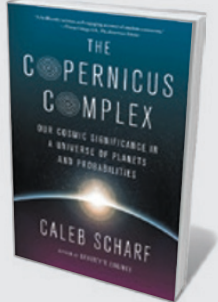

The Copernicus Complex

Caleb Scharf (Farrar, Straus and Giroux, 2015) Are we cosmically insignificant or the centre of the known Universe? Skipping from molecules to Moon landings, astrobiologist Caleb Scharf puts life on Earth under the microscope and concludes that humans are unique but unexceptional (see Mario Livio's review: Nature 512, 368-369; 2014). 